\title{
Plural practical knowledge
}

Johannes Roessler

[forthcoming in Inquiry]

\begin{abstract}
The paper examines the thesis that participants in shared intentional activities have first-person plural 'practical knowledge' of what they are jointly doing, in the sense of 'practical knowledge' articulated by G.E.M Anscombe. Who is supposed to be the subject of such knowledge? The group, or members of the group, or both? It is argued that progress with this issue requires conceiving of collective activities (of the kind affording 'plural practical knowledge') as instances, not of supra-personal agency, but of interpersonal agency; specifically: as involving communication. There is a sense, it is suggested, in which the basic form of plural practical knowledge is relational: 'I am doing $x$ with you.'
\end{abstract}

\section{I}

A number of writers have recently discussed the suggestion that participants in collective activities enjoy a plural form of what Anscombe characterized as the distinctive 'practical' knowledge an agent has of her current intentional actions. According to Frederick Stoutland, collective activities can be (in Max Weber's terms) 'subjectively understandable' as such (contrary to what he sees as Weber's own individualist strictures). They can be intelligible in terms of the participants' intentions, beliefs and perception of 'situations in the world as reasons' for them to act - but only if the agents know what they are doing, where the relevant sense of 'know' is, as Anscombe has argued, "know without observation".' By way of illustration, Stoutland mentions a corporation that 'decides to do something, and then its employees are instructed to carry out the decision'. If all goes well, 'the corporation knows what it is doing simply because its decision was carried out as intended.' (Stoutland 2008: 545-6) According to Ben Laurence, the essence of collective intentional agency lies in the way individuals' actions can be 'unified' through what he calls an 'explanation of the singular by the plural'. For example, a good explanation of why you are cracking the safe may be that we are (together) robbing a bank. The correctness of this species of reason-giving explanation, 
Laurence maintains, depends on the group, or at least some member of the group, knowing 'without observation' what they are all doing together.

Anscombe's account of practical knowledge develops from observations about the way we ordinarily make, and engage with, claims to knowledge as to what we are or will be doing. One observation is that such claims often simultaneously purport to express knowledge and intentions. Another is that there is a distinctive pattern of appropriate (and inappropriate) responses. I start by suggesting that these observations have plausible analogues in the case of collective activities, encouraging the thesis that plural practical knowledge is indeed part of our ordinary picture of intentional agency. But I will argue that problems with Stoutland's and Laurence's development of this idea emerge when we consider a natural question ${ }^{1}$ : suppose we (you and I) have practical knowledge of what we are doing together. What should be said about my knowledge of what we are doing together (and yours)? I consider three views. On what I call an 'isolationist' view, the question does not matter much: a group's possession of plural practical knowledge does not depend on the individuals knowing, let alone knowing in any particular way, what they are doing together. On what I shall call a 'distributive' view, plural practical knowledge is not just something we have, collectively; each of us, on our own, has it too. I shall present objections to both views and put forward an alternative, which I call a 'relational' view. According to this view, if we have plural practical knowledge of being engaged in some activity, then we both must have practical knowledge of acting with each other; more precisely: practical knowledge we could articulate by the use of the first- and second-person pronoun, 'I'm doing $x$ with you'.

\section{II}

Suppose A directs the following question at B and C: "Why are you two beating out that curious rhythm?' And suppose B and C jointly reply 'We are rehearsing our parts

\footnotetext{
${ }^{1}$ In thinking about this question I have benefited greatly from Guy Longworth's illuminating critical discussion of what he calls shared non-observational knowledge (see Longworth, forthcoming).
} 
in the Rites of Spring.' The interpretation friends of plural practical knowledge wish to place on examples such as this turns on three distinctions.

First, on a natural reading, A's question involves a collective predicate, one whose application 'fails to license the downward implication to individual things.' ${ }^{2}$ (Unlike 'distributive' predicates, which do license just that implication.) 'You are (both) beating out a curious rhythm' might be construed distributively, as entailing that $B$ is beating out a curious rhythm, as is C. But A's question is most naturally heard in a way that is non-committal on what rhythm, if any, B or C are beating out on their own.

Second, A's question is a special example of a use of 'Why?' Anscombe invokes in her 'definition' of intentional actions. She characterizes intentional actions as those 'to which a certain sense of the question 'Why?' is given application', the sense in which 'the answer, if positive, gives a reason for acting.' (1957: 9) What is distinctive about $A^{\prime}$ 's question is that it is naturally heard as a request, not for B's or for C's reason for acting (or for both), but for the reason for which $B$ and $C$ are together engaged in their percussive activity. As Laurence puts it, the normative question 'Why?' has a special 'collective action' sense, to be distinguished from the 'individual action' sense that figures in Anscombe's discussion.

Third, B and C's reply is naturally interpreted as an example of what Anscombe calls an expression of intention. The mark of an expression of intention is that in response to it, the request for evidence would be off-key, whereas the request for a practical reason would normally be appropriate. (1957: 2-7)

If this interpretation of the exchange is on the right lines, it is tempting to make certain further claims, in parallel with Anscombe's treatment of individual intentional actions. One is that it is a necessary condition of $A$ 's special 'reason-

\footnotetext{
${ }^{2}$ See Smiley and Oliver 2013:113. One example of a collective predicate is 'weigh(s) more than $100 \mathrm{~kg}$ ', which 'can be true of some things without being true of each of them'.
} 
seeking' question having application that $B$ and $C$ possess non-observational knowledge of what they are doing together. As in the individual case, if $B$ and $C$ had no idea they were beating out a certain rhythm, or only knew they did because they discovered it through listening carefully to the sounds they were producing, the request for a reason for their activity, under that description, would fall to the ground.

This move seems no less plausible than Anscombe's analogous move in the individual case, and this in turn encourages a further suggestion: B and C's knowledge of what they are doing together is an example of 'knowledge in intention' or 'practical knowledge'. Just what this is supposed to mean is contentious, of course, but I think there is broad agreement on two basic points, a negative and a positive point. If you have 'knowledge in intention' of doing $x$ then your knowledge that you are doing $x$ is not to be explained by reference to any way of finding out what you are doing (whether observation, inductive reasoning, testimony, or whatever), and the request for such an explanation would strike us as out of place. The positive point suggests a rationale for this. We are, under certain conditions, entitled to answer the question of what we are or will be doing by expressing our intentions, either in the present progressive or in the future tense. That is, we may be entitled to treat the factual question of what we are or will be doing as a practical question. We can make a warranted claim to knowledge by expressing a practical choice (which may, but does not have to, be made at the same time we are expressing it). The entitlement is conditional on avoiding two sorts of mistakes: mistakes in performance (as "when I say "Now I press button A" - pressing button B.' (1957: 57)) and mistakes in practical judgement (as when 'I go out in Oxford with a shopping list including 'tackle for catching sharks' (1957: 56)). In the first case, the intention may reflect sound practical reasoning but it may fail to get executed. If so, of course, one would not be speaking truly in saying what one is doing and so one's claim would not express knowledge. In the second case, one would express an illjudged, unrealistic intention, one that is not properly informed by knowledge of one's practical abilities or the means available to one for accomplishing one's ends. Note that even if one miraculously succeeded in obtaining tackle for catching sharks 
in Oxford, one's claim 'I'm buying tackle for catching sharks in Oxford' or 'I shall buy tackle for catching sharks in Oxford' would not express knowledge if, for all one knew, this product was not on sale in Oxford. ${ }^{3}$

Applying this to the case of B and C's answer, we might say that the request for an account of how they are able to find out what they are doing would strike us as offkey since we respect their entitlement to pronounce on what they are doing by expressing their intention. Assuming a flawless exercise of practical judgement ${ }^{4}$ and a glitch-free execution, B and C's answer is plausibly interpreted as an expression, simultaneously and connectedly, of their intention and their knowledge. This would be a significant result. One philosophical question in this area is whether collective activities can be genuine cases of intentional agency. Of course, one answer would be that they can, insofar as they amount to nothing other than a complex combination of individual intentional activities. But it is far from clear that a credible reductive account of collective intentional agency is in the offing. Part of the promise of the idea of plural practical knowledge, I think for both Stoutland and Laurence, is that it offers the prospect of a non-reductive account. How can a collective action be intentiona/? Part of the answer, it might be said, is this: participants in a collective activity can have the sort of knowledge possession of which, as Anscombe taught us, is part of what it means to be acting intentionally, viz. 'practical knowledge' of what they are doing.

III

It does not detract from that promise to raise the following question. $B$ and $C^{\prime}$ s practical knowledge, as characterized in the previous section, is collective in more than one sense. It is knowledge of what they are doing together. It is also knowledge they are expressing together. Crucially, what makes it natural to treat their knowledge as an example of practical knowledge - what renders the question 'How

\footnotetext{
${ }^{3}$ For discussion of he nature of this entitlement, see Falvey 2000. On the importance of avoiding mistakes in judgement, see Roessler (forthcoming).

${ }^{4}$ At least, 'flawless' in relation to feasibility. The epistemology of practical knowledge does not impede knowledge of pointless or evil acts.
} 
did they find out?' off-key - is that their claim is naturally taken to express their intention and to reflect their (sound) practical judgement. Their knowledge, then, is not just knowledge of a collective activity, but it is knowledge that is collectively owned. The question I want to raise is this: what implications, if any, does their collective possession of knowledge have for each of the participants' epistemic position? Does it imply, for example, that each of them has practical knowledge of what they are doing together?

An uncompromising anti-reductionist might be tempted to retort 'it has no such implications whatsoever'. That the two of us are beating out a curious rhythm together does not entail that either of us is beating out a curious rhythm. Quite generally, it is hazardous to make inferences about an individual on the basis of attributions of collective predicates to a group to which the individual belongs. In keeping with this, one might take the subject of plural practical knowledge to be simply insulated from questions about an individual's knowledge of a collective activity in which she is participating. I will not pursue this 'isolationist' view in detail. I think it is hard to sustain, at least given the 'analogical' way I have introduced the idea of plural practical knowledge. If $A$ and $B$ know (together) what they are jointly doing, I suggested, they are disposed, in response to a reason-seeking question addressed to them (in the plural) to express their shared intention. ${ }^{5}$ Now, if the second-person-plural reason-seeking question has application, it is hard to see how it can be off-key to pose certain associated singular reason-seeking questions to an individual participating in the joint enterprise, such as the question 'Why are you taking part in this activity?' And the appropriateness of the latter question presupposes that the individual knows she is participating in the undertaking, where

\footnotetext{
${ }^{5}$ Margaret Gilbert argues for a view of shared intention that may lead one to deny this. She maintains that Tina and Lena's shared intention to go for a 30-minute walk endures even when, after ten minutes, Lena decides to go back. (2000:18) At that point, it seems reasonable to suppose, Lena and Tina will not be disposed to express what Gilbert insists is still a shared intention. I'm not convinced by Gilbert's claim that her example is tracking 'our everyday concept of shared intention' (ibd.), though - I suspect it is a hyperbolic expression of the plausible view that shared intentions cannot be reduced to what she calls personal (i.e. individual) intentions.
} 
this in turn involves at least some notion of which undertaking she is participating in. ${ }^{6}$

IV

I have motivated the idea of plural practical knowledge by reference to a fairly strict parallel between the case of individual and collective intentional activities. The parallel turns on the connection between intentional agency and second-person 'reason-seeking' questions, as elaborated by Anscombe. It might be said, though, that there is something a little artificial about my strict reading of the parallel: I had $A$ and $B$ not only acting together and being the joint addressees of the secondperson plural question 'why?' but even expressing their plural intention together. There is of course room for debate about what counts as jointly expressing an intention. This may not require a collective speech act. Perhaps a spokesperson may speak on behalf of the participants. Be that as it may, Laurence favours a more liberal construal of the parallel. In his illustrations, individuals participating in a collective activity are seen to express plural intentions all by themselves. For example, a member of a team pushing a car up a hill, individually queried about the point of the collective enterprise, explains 'we are pushing it to the gas station'. As Laurence tells the story, we are encouraged to think of this as an expression of the individual agent's practical knowledge of what they are all doing together. This seems to reflect a distributive view of plural practical knowledge: roughly, those engaged in a collective intentional activities have plural practical knowledge, not only jointly but also individually, of what they are collectively doing. To be more precise, Laurence holds a qualified distributive view. He thinks that in the case of hierarchically organized groups, particular agents may lack non-observational knowledge of what the group as a whole are doing, under descriptions under which the collective activity is intentional. They may defer to those in charge of planning the whole operation. What matters, on Laurence's account, is that 'some suitably

\footnotetext{
${ }^{6}$ The isolationist view is implicit in Stoutland's discussion. He treats the attribution of practical knowledge to a corporation as neutral on the question of what knowledge, if any, individual members have of the corporation's activity.
} 
placed person(s) must know without observation what purposes the group is pursuing.' (2011: 288)

I now present two objections to the qualified distributive view. ${ }^{7}$

There is, first, a question about the coherence of Laurence's liberal version of the parallel. In the car pushing example, Laurence imagines asking 'one of them' (one of the several men pushing a car) 'Why are you pushing the car up the hill?' The interpretation of that question is not straightforward. 'You', it is reasonable to think, refers to the person, or people, the speaker is addressing. That is the reference rule for the second person, singular or plural, respectively. Accordingly, given that Laurence is addressing 'one of them', he must be using the second-person singular pronoun. Yet it later emerges that it is the second-person plural pronoun he seems ot have in mind. For Laurence re-phrases his question thus: 'Why are you all pushing the car?' The re-phrasing reflects Laurence's concern with the 'special collective action sense' of 'Why are you doing $x$ ?' The problem is that in that sense, the question must be addressed to more than one agent. It is not a question that can be coherently posed to 'one of them' ${ }^{8}$

The most charitable construal of the liberal reading is that the question put to 'one of them' is this: 'Why are you [singular] and these other people jointly pushing the car up the hill?' On this construal, the liberal reading is committed to separating two roles that, in Ancombe's discussion, are invariably co-occupied. The addressee of the reason-seeking question, in the case of the 'special collective action sense', is not the agent whose reasons are being sought. (He is merely one of them.) This gives us a coherent account, but it leads to a further objection, which turns on what might be

\footnotetext{
${ }^{7}$ In thinking about this I've benefitted greatly from conversations with Glenda Satne. For further discussion of Laurence's account, see the two papers by Satne listed in the bibliography.

${ }^{8}$ There may be room for debate as to whether the second-person plural can be addressed to a single speaker if she acts as a spokesperson for a group. (I am grateful to an anonymous referee for drawing my attention to this.) But this is not something Laurence's discussion of the example exploits.
} 
called the issue of authority. How should we understand the authority of the addressee's account of the reasons for which the collective activity is being undertaken? Hans Bernhard Schmid has pressed this in a recent discussion that is critical of the very idea of plural practical knowledge. He writes:

"what I take "our intention" to be does not settle the question of what it is we're doing together in the same way it does in the case of my own intentions.'

'If you tell me what you intend to do, individually, it does not make much sense for me to ask how do you know what it is you intend. You just know, that's it. But if you tell me that's what you intend to do together with your partner, no such reply seems to be possible. You don't "just know".' (2016: 61-2)

It is not entirely clear whether Schmid is concerned here with self-ascriptions of intentions, or statements about what one is or will be doing, or both. Let's focus on statements of one's activities (which the context suggests is at least part of what he has in mind). Then Schmid's challenge may be put like this:

(i) The question 'How do you know?' is off-key in response to statements expressing, or purporting to express, practical knowledge of what one is or will be doing.

(ii) The question 'How do you know?' is not off-key in response to an individual's first-person plural statements about activities in which she is participating.

(iii) Therefore, first-person plural statements about activities in which one is participating do not express practical knowledge.

Two clarifications are in order. First, l've already touched on the rationale for (i) but let me emphasize that (i) needs to be carefully distinguished from the idea that the statements in question are immune to error, or immune to any sort of challenge regarding their credentials. Such statements can be wrong in perfectly intelligible ways. Recall: if you make an 'error in performance', you might tell us 'I'm pressing 
button $A^{\prime}$ when in fact you are pressing button B. (Let's suppose these buttons can only be pressed once, so you have no opportunity to rectify your inept performance.) Furthermore, ill-informed practical reasoning might lead you to tell us 'I am buying tackle for catching sharks in Oxford today', when in fact tackle for catching sharks 'is not to be had' in Oxford. (Anscombe 1957: 56) A closely connected point is that there are in fact natural ways of probing or challenging such statements, say 'Are you sure they sell that sort of thing in Oxford?' The challenge targets the practical reasoning informing your intention, in particular your entitlement to rely on particular premises. What (i) insists would be inappropriate is a request for an account of how you know what you claim to be the case, where this is naturally understood as a request for an account of how you were able to find out or discover that it is the case. As indicated, the rationale for deeming this latter sort of request inappropriate has to do with the nature of expressions of intention. When you express your intention to do $x$ by saying ' I'll do $x$ ' you regard the question of whether you will do $x$ as a practical question, to be answered by considering your practical reasons for doing $\mathrm{x}$. What is hard to see is how one can take one's statement to be warranted, simultaneously, in the light of such practical reflection and by reference to one's exploiting some way of finding out what one is or will be doing. It seems to be built into the former style of reflection that it is up to one whether one will do $\mathrm{x}$. It seems to be built into the latter style of reflection that there is an independent fact of the matter for one to discover.

Second, 'off-key' means more than 'brusque' or 'tactless' or 'conversationally inappropriate'. 'How do you know you and these other people are pushing the car to the gas station?' may be any of the latter, yet, so Schmid would insist, it is not offkey, where this might be glossed as: 'leaving us at a loss as to what would count as a good answer', or 'erroneously presupposing that the addressee knows about the fact in question by exploiting some way of finding out'. On Schmid's analysis, the obvious way to answer our question would be to report on the deliberation that went into 
the shared intention to push the car to the gas station. ${ }^{9}$ 'I know this is what we are all doing', he might say, 'because it's what was agreed when we discussed the matter.' Thus our informant's authority is really that of an eyewitness of the relevant deliberation. (Whether he participated in the deliberation would seem immaterial.) In Anscombe's terms, what he has is 'speculative knowledge'.

The force of Schmid's challenge, then, is this. So long as our questions as to what the group are doing, and why they are doing it, are addressed to an individual participant in the collective activity the authority of our interlocutor's response will be theoretical, not practical. He cannot settle the question of what the group are doing by deciding what to do, or by expressing his individual intention. That is why his answer, if knowledgeable, will be an example of speculative, not practical knowledge. One reaction would be to insist that in telling us 'We are pushing the car to the gas station' he is acting as a spokesperson, expressing not his own individual knowledge but an intention (and simultaneously practical knowledge) belonging to the group. This, though, would bring no solace to the distributive view. If he is expressing the group's intention and knowledge, the question of how to understand an individual's knowledge of what the group are doing remains wide open. ${ }^{10}$

\footnotetext{
9 'If we are walking together, I may have whatever epistemically groundless (or perhaps introspective) knowledge of what it is $I$ am doing. As far as your part is concerned, however, I better recall correctly what exactly it was we've agreed to do together.' (Schmid 2016: 61) (The context suggests Schmid would take the same line about my knowledge of what it is we are doing together.)

${ }^{10}$ As an aside, let me briefly consider how the qualification that makes Laurence's a qualified distributive view bears on the current challenge. There are, according to Laurence, conditions under which an individual's ignorance that the group are doing $\mathrm{x}$ is no bar to the 'special collective action sense' of the reason-seeking question 'why?' finding application and thus no bar to describing the group as intentionally doing $\mathrm{x}$ together. The conditions he has in mind are roughly relations of authority and/or trust. For example, Laurence thinks the captain of a ship may have practical knowledge of what the crew as a whole are doing together, say executing a turn to starboard, even if many members of the crew have no inkling that they are participating in the activity, under that description. (2011: 290) There is, on Laurence's account of this sort of case, an intelligible link between the captain's individual practical reasoning and the collective intentional activity: in virtue of his position in the hierarchy he is able to settle what the group are doing, and so able to express his knowledge of what the
} 
The suggestion I would like to put forward develops from the following diagnosis. Laurence's and Stoutland's discussions of practical knowledge of collective activities, for natural and intelligible reasons, focus on analogies between first-person singular and first-person plural claims to knowledge of intentional agency. The former is thought to provide a model, in certain respects, for understanding the latter. While this perspective is surely illuminating, there are distinctive features of the plural case that do not come into view so long as we confine ourselves to the analogical perspective. It is because of this that the analogical perspective makes it look puzzling, in the ways I have been laboring, how to understand the implications of plural practical knowledge for the epistemic perspective of an individual who shares in it. One way to put this complaint is that the analogical perspective fails to give sufficient weight to the fact that collective intentional activities are not merely a matter of groups exercising their supra-personal powers of agency: it also, essentially, involves inter-personal agency among the individuals making up the group. To get this into focus it is instructive to consider a style of thinking and talking

group are doing by expressing his intention, say 'we are executing a turn to starboard'.

The problem with this analysis is not that the crew might go on strike, frustrating the captain's carefully reasoned intentions. So long as they are in fact disposed to carry out their superiors' orders, and the captain knows they are, he can surely know what they are all doing together. Compare: a man operating a pump may know that he is replenishing the water supply of a country house, even if the pump might not have been operational, so long as it is in fact operational, and the man knows it is. Rather, the problem can be put in the form of a dilemma. Either the captain is a sociopath who thinks of his subordinates as a mere mechanism for achieving his aims, similar to the mechanism underpinning the operation of a pump. If so, his practical reasoning will only issue in first-person singular statements, such as 'I'm executing a turn to starboard (utilizing the machinery at my disposal)'. It will not provide him with practical knowledge of what they are all intentionally doing together. Or he thinks of his subordinates as people who act for what they consider to be good reasons. If so, he will realize that his individual practical reasoning can only take him as far as issuing orders. While he has practical knowledge that he is ordering the crew to execute a turn to starboard, his knowledge that they are all collectively executing a turn to starboard is not practical knowledge. If someone were to ask him 'How do you know the whole crew are doing this together?' he would have a ready answer, displaying the 'speculative' nature of his knowledge: 'I know this because I've given them orders to that effect, which they are trained (and paid) to carry out.' 
about collective activities that the analogical perspective is apt to overlook. Asked what she was doing, B might naturally reply thus:

(1) I'm rehearsing the Rites of Spring with C.

Let's call this a relational form of expressions of shared intentions. It is worth noting straight away some points of contrast with (2):

(2) We are rehearsing the Rites of Spring.

One difference is simply that (1) is more informative: it tells us who is involved in the shared activity, as (2) may not (depending on the context). But connectedly, (1) makes explicit something (2) does not, that there is a certain relation of mutual dependence between B and C. We can bring this out by asking whether (1) is in fact an expression of intention at all. On the one hand, (1) does seem to invite questions about relevant practical reasons, as expressions of intentions do. On the other hand, in asserting (1) B commits herself to $C$ participating in the shared activity with her, and, as Schmid points out, this is not something B is in a position to 'settle', in the sense in which we are able to settle our own intentions. It is because of this commitment that (1) may intelligibly prompt enquiries such as 'How do you know C is up for this?' (The question may sound a little odd in response to (1), but it is less so in cases where it targets a future tense version of (1): 'I'll be rehearsing the Rites of Spring with $\mathrm{C}$ in the afternoon.')

It is instructive to compare that enquiry with the question 'How do you know they are selling tackle for catching sharks?', discussed earlier in connection with Anscombe's example. Neither question is asking after the agent's way of finding out what they are doing. Rather, the questions request an account of a different, though related piece of knowledge, a piece of knowledge that is clearly 'speculative' (hence 'How do you know?' is plainly appropriate) but partly accounts for the agents' entitlement to her claim to practical knowledge of what they are doing. Unless you know that tackle for catching sharks is for sale, you have no business claiming you 
are buying it. Unless you know $\mathrm{C}$ is cooperating, you have no business claiming you are cooperating with him. But there is, arguably, also a notable difference between the two cases. Ill-informed practical reasoning can certainly issue in the formation of an intention. When the futility of her shopping trip is revealed, the agent may retreat to something like this: 'I wasn't, it turns out, buying tackle for catching sharks ${ }^{11}$, but I certainly intended to do be doing so.' By contrast, if $\mathrm{C}$ has no interest in a group rehearsal, this seems to leave $B$ in a worse position than that of having an intention that has no chance of success. It is not open to $B$, in that case, to retreat to the statement 'I was not, it turns out, rehearsing together with C, but I certainly intended to be doing so.' How could B, on her own, even intend to rehearse together with $C$ (given that, on her own, she lacks the capacity to 'settle' whether to rehearse together with $\mathrm{C}$ )? There is a familiar device one might be tempted to use here: perhaps B intended that she and C play together. Yet, arguably, this could only mean that she intended to bring it about, or do what she can to bring it about, that she and C play together. (See e.g. Stoutland 2002) If the intention B means to be expressing, to play together with $C$, is a shared intention, it is not an intention $B$ could possess by herself. C's indifference therefore means B is mistaken not just about what she is doing, or involved in doing, but about an aspect of her own mind. She thinks she is partaking in a certain shared intention, but she is wrong about this. It is not that she has an ill-considered intention, as the shopper in the sharks case does. Rather, there is no intention to consider. In uttering (1) she is not even succeeding in expressing an intention $!^{12}$

The mutual dependence between agents who share an intention, then, has both a practical and a psychological dimension. We depend on others' cooperation for

\footnotetext{
${ }^{11}$ Lack of success is certainly compatible with the truth of the (past progressive statement) 'she was buying tackle for catching sharks'. Compare: 'She was buying tackle for catching sharks when aliens abducted her.' But impossibility of success is arguably not. 'She was buying tackle for catching sharks, though it was not to be had' does not seem quite right. For discussion of the truth conditions of attributions of activities in the present or past progressive, see Falvey 2000, Thompson 2011, Wolfson 2012.

${ }^{12}$ That is not to say that she has no relevant intention whatsoever. Presumably she does intend to contribute her share to what she thought would be a joint activity.
} 
getting things done, in cases where we are unable to do so by ourselves. But we may also depend on others' cooperation for engaging in the activities we think we are engaging in, and even for having attitudes of the sort we take ourselves to be expressing when we make claims such as (1). At a certain level of abstraction, this latter form of dependence might be compared to 'externalist' views of perceptualdemonstrative thoughts, on which such thoughts are only available if there is an object to be thought about. ${ }^{13}$ The recent literature offers a variety of perspectives on the suggestion that we need to recognize a distinctive 'interpersonal' variety of externalism - distinctive, partly, in that the thought-affording dependence is a mutual one. One is Richard Moran's development of Reid's notion of a 'social act', an interaction between two agents that 'necessarily involves both people in mutual awareness, and with both parties understanding the part each plays in the act in question.' (2018: 149) Moran's interest lies in illocutionary acts such as telling or asking, in which the two participants play complementary roles defined by the nature of the act in question. There are, correlatively, clearly defined relations of mutual dependence in these cases: I count as telling you something only if you recognize that this is what I'm doing. As Moran puts it, the success of my act 'consists in such recognition.' (2018: 151) A striking feature of Moran's discussion of 'social acts' - especially striking when contrasted with the dominant trends in current work on collective agency - is that he is neither seeking to reduce social acts to individual acts performed, potentially independently of each other, by the participants (though he is certainly interested in what individual contributions are required for the possibility of given kinds of social acts) nor tempted to attribute social acts to some sort of supra-individual agent such as a group mind or a 'plural subject'. On Moran's account, 'social acts' are essentially, and irreducibly, relational.

It may seem that while the success of what Moran calls a social act depends on both participants playing their respective role in the act, the intention to perform such an act is not essentially shared. If your attempt to tell someone that $p$ is unsuccessful, owing to her refusal to listen, it may still be right to say that you intended to tell her

\footnotetext{
${ }^{13}$ See Eilan (forthcoming) for illuminating discussion of the comparison.
} 
that p. Arguably, though, the stronger form of dependence is implicit in Moran's view that the sorts of social acts he is concerned with essentially involve secondperson thoughts and intentions. Second-person thinking, it has been argued - and Moran would seem to agree - , essentially depends on the addressee's disposition to recognize being addressed; in Moran's words, it involves 'a content and act that is the object of shared recognition'. On such a view, only if you have the required dispositions will I be able to have a second-person intention to tell you that $\mathrm{p}^{14}$

\section{VI}

Consider now the following suggestion. There is a sense in which the relational form of plural practical knowledge is basic. More specifically, what is basic is a secondperson version of the relational form. Shared practical knowledge that 'we' (you and I) are doing $x$ depends on our being in communication with each other, enabling us to articulate our practical knowledge by saying 'I'm doing $x$ with you'. (In the case of larger groups, we need to be able to articulate our knowledge addressing each of the participants.) Of course, there will often be no point in making our activity explicit in this way. What matters is that we are both in a position to do so insofar as we are communicating with, and able to address, each other. It is this that makes it possible for us to 'settle' together what to do and to acquire an intention that is 'the object of shared recognition'.

One attraction of a 'relational view' along these lines is that it promises to make the issue of an individual's possession of plural practical knowledge tractable. According to the relational view, attributions of plural practical knowledge do have implications for the epistemic position of the individuals making up the group (contra the isolationalist view), but they do not imply that each (or some) of the individuals in question has such knowledge all by themselves (contra the distributive view). What is implied is that the individuals are in a position to share relational - first- and second-person - knowledge of what they are jointly doing.

\footnotetext{
${ }^{14}$ This conclusion depends on the controversial assumption that the use of 'you' involves a distinctive way of thinking of the addressee. For discussion, see Longworth 2014, Eilan 2014.
} 
In particular, the relational view promises an effective response to Schmid's challenge, a response that is not available to the distributive view. Schmid is right that in view of B's inability, on her own, to 'settle' whether she and C rehearse together, she cannot have practical knowledge, by herself, that they are. But in uttering (1) B is not entering a claim to 'individual' practical knowledge. She's making a claim to be engaged in a joint intentional activity with $\mathrm{C}$, a claim that purports to be an expression of an intention (and practical knowledge) shared with C. Thus in uttering (1) B lays herself open to questions about a salient prerequisite of her entitlement to that claim, viz. whether and how she knows $C$ is cooperating. However, by establishing that the prerequisite is met, she can vindicate her entitlement to a claim to practical knowledge, and thus reasonably repudiate Schmid's, or anyone else's, request for an account of how she knows that she is rehearsing with $\mathrm{C}$.

\section{VII}

To spell out the commitments of the relational view, it is useful to return to the issue of the scope of collective intentional agency. Some authors - among them Laurence and Stoutland - favour a broad, inclusive view of this, licensing the attribution of intentional activities to groups not all members of which are privy to the activity (under all descriptions under which the activity is collectively intentional) and even to institutions, individuated in ways other than by reference to their current membership. Other authors adopt a notably narrow and exclusive view. For example, Velleman writes:

'shared intention is not supposed to be a matter of one person's deciding or planning the activities of a group; it's supposed to be a matter of shared intending, in which each member of the group participates equally in forming and maintaining the intention, fully recognizing others as equal participants.' (2000: 205) 
The relational view, I want to suggest, steers a plausible middle course between these extremes.

The inclusive view seeks to understand phenomena of collective agency at a high level of generality. But it is surely not obvious that the same account should be given of the sense in which, on the one hand, two musicians rehearsing Stravinsky and, on the other hand, a large corporation pursuing a profit may be said to be engaged in a collective intentional activity. I suggested earlier that part of the promise of appealing to plural practical knowledge in explaining shared intentional action was to secure a strong sense of univocity: participants in a collective activity can have the sort of knowledge possession of which is arguably part of what it means to be acting intentionally. I also argued that there is good reason to withhold the attribution of plural practical knowledge in the case of the activities of hierarchies (some members of which have, at best, speculative knowledge of the collective activity). It would be a mistake to take these suggestions to be mutually inconsistent, or to disable us from acknowledging that institutions can, in some sense, act intentionally. It is in any case not implausible to think of that latter sense as an extension from, rather than an instantiation of, the core notion we use in reflecting on we are doing, individually or jointly. ${ }^{15}$ Intentional activities, in the core sense, are a proper target of reasonseeking questions and are paradigmatically open to explanations by reference to the agent's (or agents') practical reasons. In the case of collective actions, the satisfaction of that condition, minimally, requires communication among the participants.

So far the relational view is in agreement with Velleman's account, which stresses the importance of 'recognizing' each other as 'as equal participants'. There is, though, a question as to what this involves. According to Velleman, only if we 'participate equally in forming and maintaining the intention' can we be said to share the intention. On a weak reading, 'equally' just means that we both need to play some role in forming and maintaining the intention. But Velleman apparently has a

${ }^{15}$ See List \& Pettit 2011 for illuminating discussion of ontological and normative issues raised by the idea of what they call corporate agents. 
stronger claim in mind, that we need to play, and to recognize each other as playing, the same kind of role; that we need to have the same kind of, as he puts it, 'discretion' over what we are doing together. Yet, on the face of it, shared intending is consistent with significant inequality in respect of 'discretion': compare a conductor and members of the orchestra, parents and children, bullies and their victims, perhaps masters and their slaves. Relations of mutual address may entail a certain minimal sense of 'mutual recognition', roughly as persons capable of acting for what they regard as good reason, but such relations do not exclude the possibility of highly 'unequal participation' in forming and maintaining shared intentions. That possibility raises further substantive questions (Can we be specific about the limits of inequality? Might there be a sense in which such cases are less than paradigmatic examples of shared intentions?), which the relational view, as stated, leaves open.

\section{VIII}

The relational view helps itself to the idea that participants in shared activities jointly settle what they are doing, and a detailed development and defence of the view would need to say more about what this involves. I want to conclude by contrasting two perspectives on this question.

To say that 'joint settling' is a necessary condition of joint intentional agency may seem to invite a charge of circularity. Reaching a decision together, it will be said, is itself a joint intentional activity, so we should avoid appealing to the former in giving an account of the nature of the latter. I think a preoccupation with circularity plays a significant role in Velleman's approach to shared intending (and in this respect, of course, he is representative of a wider trend). Discretion, he maintains, 'ordinarily seems indivisible' (2000: 205). Part of what this means is that practical reason can only be exercised individually, yielding first-person singular intentions. Velleman provides no clear rationale for this assumption, though. He observes that 'one person's exercise of discretion over some issue would seem to exclude any other person from exercising discretion over the same issue.' (205) If I am settling what we are to do, I cannot simultaneously think of the matter as up to you. Yet, suppose we 
are jointly settling what we are to do. Then we can think of the matter us up to us. Velleman does not consider this move. I think the reason he does not consider it is that he takes it to be obvious that appeal to shared 'settling' would render our account of shared agency viciously circular. ${ }^{16}$

That is one perspective. An alternative perspective, congenial to the relational view, can be found in the following passage from a recent paper by Dorothea Frede, on Aristotle's treatment of collective agency:

(..) the question of how two or more people manage to form a decision to act jointly did not much exercise Aristotle. If one wonders why he did not see a problem there, the answer suggests itself that such joint decisions have their practice as well. Once familiarized with such a practice-e.g., to agree to play a game of checkers - it does not much matter how a particular decision is made. Two people may do so routinely and therefore one or the other may suggest doing so, or a match may be due to a special occasion, such as a tournament. What matters is only that at some point agreement has been reached to play checkers together. Playing against oneself is clearly a derivative activity. The background reasons to perform a particular joint action may be as varied as those to perform a singular action. And a universal account of how such decisions come about is just as formal as the determination of a decision to perform an act by one person, except for the fact that in the former case communication of some sort must have taken place. This is even true in the case that a wish to do a certain action should arise simultaneously and spontaneously in two people that has been performed many times: Sometimes a gesture may suffice, sometimes long negotiations may be necessary. (Frede 2016: 54)

I want to highlight two suggestions that can be extracted from this passage. One is that jointly settling what to do does not have to take the form of a joint activity

\footnotetext{
${ }^{16}$ For direct evidence of Velleman's preoccupation with circularity, see 2000: 219-20.
} 
that's intentional under a description such as 'we are settling what to do'. A sensibly pluralist account will recognize the enormous variety of ways in which people start shared enterprises. If $B$ absentmindedly beats out her part in the Rites of Spring and $C$ joins in, they may find themselves spontaneously rehearsing their parts together. (There is communication involved here, but it may take the form of communicative glances or communicative percussion rather than verbal communication.) Again, 'a gesture may suffice' to attract someone's attention and thus to start a conversation. The sense in which agents jointly settle what they are doing, in such a case, may come to something like this: both agents perform their respective parts in a shared activity of which they are mutually aware.

The second suggestion is a response to a complaint that might be prompted by the pluralist picture. The complaint is that cases in which we spontaneously start a joint activity are really (at least typically) cases in which we spontaneously re-start an activity we have been intermittently engaged in together, such as rehearsing or communicating. The complaint, in other words, is that the proposed account presupposes and therefore cannot explain the acquisition of shared intentions. I think the complaint gets something right. On Frede's Aristotelian picture, the 'practice' to which we should appeal in understanding the manifold ways of coming to share intentions is itself a shared practice. We acquire the relevant skills by coming to participate in the shared activities that go into the practice. If a satisfactory philosophical understanding of shared intending is expected to explain how it is possible for shared intentions to emerge from a situation in which there are no shared intentions, but only first-person singular intentions, then, it is true, Frede's picture should leave us dissatisfied. The response that I think is encouraged by Frede's discussion is that we should question the individualist presuppositions of the putative condition of adequacy. It is not clear, for example, that only a reductive picture would be properly informative. Nor, even granting that a reductive account would be a good thing, is it clear that such a thing is to be had. For example, one might question, in a Vygotskian vein, whether the ability to form first-person singular intentions is available independently of the ability to participate in shared intending. 
It is conceivable that, like playing a game of checkers against oneself, the activity of solitary practical deliberation is a derivative activity. ${ }^{17}$

\section{References}

Anscombe, E. 1957: Intention. Oxford: Blackwell. Eilan, N. 2014: 'The you turn', Philosophical Explorations 17, No. 3, 265-278.

Eilan, N. (forthcoming): 'Other I's, Communication and the Second Person', Inquiry (this special issue)

Falvey, K. 2000: 'Knowledge in Intention', Philosophical Studies 99, 21-44.

Frede, D. 2016: 'The Social Aspects of Aristotle's Theory of Action', Philosophical Topics 44, No. 1, 39-57.

Gilbert, M. 2000. 'What is it for us to intend?', in her Sociality and Responsibility. Oxford: Rowman \& Littlefield.

Laurence, B. 2011: 'An Anscombeian Approach to Collective Action, in A. Ford, J. Hornsby \& F. Stoutland (eds.), Essays on Anscombe's Intention. Cambridge, Mass.: Harvard University Press.

List, C. and Pettit, P. 2011: Group agency: The possibility, design, and status of corporate agents. Oxford: Oxford University Press.

Longworth, G. 2014: 'You and me', Philosophical Explorations 17, No. 3, 289-303.

- (forthcoming): 'Sharing non-observational knowledge' Inquiry (this special issue) Moran, R. 2018: The Exchange of Words. Oxford: Oxford University Press.

Satne, G. (forthcoming): 'Understanding others by doing things together. An enactive account', forthcoming in Synthese

Satne, G. (forthcoming): 'Practical Knowledge and Shared Agency: Pluralizing the Anscombean view' Inquiry (this special issue)

Smiley, T. and Oliver, A. 2013: Plural Logic. Oxford: Oxford University Press.

Roessler J. (forthcoming): 'Practical Knowledge and Testimony', in R. Teichmann (ed.), The Oxford Handbook of Elizabeth Anscombe. Oxford: Oxford University Press. Schmid. H.B. 2016: 'On Knowing What We're Doing Together: Groundless Group Self-Knowledge and Plural Self-Blindness', in M. Brady \& M. Fricker (eds.), The epistemic life of groups: Essays in the epistemology of collectives. Oxford: Oxford University Press.

Stoutland, F. 2002: 'Review of M. Bratman, Faces of Intention: Selected Essays on Intention and Agency', Philosophy and Phenomenological Research 65, No. 1, 238241.

- 2008: 'The Ontology of Social Agency', Analyse \& Kritik 30, 533-551.

${ }^{17}$ A previous version of this paper was presented at workshops in Santiago and Cambridge. For discussion and comments I'm grateful to Tom Crowther, Naomi Eilan, Jane Heal, Diego Lawler, Guy Longworth, Lubomira Radoilska, Abraham Roth and Glenda Satne. I'd also like to record my gratitude to the British Academy for awarding Glenda and me an International Mobility Grant that made the Santiago workshop possible. 
Thompson, M. 2011: 'Anscombe's Intention and Practical Knowledge', in A. Ford, J. Hornsby \& F. Stoutland (eds.), Essays on Anscombe's Intention. Cambridge, Mass.: Harvard University Press.

Velleman, D. 2000: 'How to share an intention', in his The Possibility of Practical Reason. Oxford: Oxford University Press.

Wolfson. B. 2012: 'Agential Knowledge, Action and Process', Theory 78, 326-57. 